2 Research evidence suggests that:

a $10 \%$ of young people who have been in care go on to become young prisoners

b looked after children are 10 times more likely to be excluded from school than their peers

c of young women leaving care, $25-30 \%$ are parents

d young people leaving care have a 1 in 10 chance of become homeless

e recent government figures show an improvement in the educational attainment of looked after children.

3 From the research:

a in one local authority, $67 \%$ of looked after children had a psychiatric disorder, compared with $15 \%$ of the comparison population

b many children in care show high levels of comorbidity

c the most common disorders exhibited by looked after children are conduct disorders and depression

d young people in foster care experience greater mental health problems than those in residential care

e $8 \%$ of looked after children in one local authority had a diagnosis of unspecified functional psychosis.

4 Which of the following are true?

a the main reason children and young people enter the care system is family dysfunction

b many of the problems experienced by looked after children are severe, complex and of long duration

c we have information on how many looked after children use adult mental health services in later life

$\mathrm{d}$ we need national data on the type and prevalence of mental health problems in looked after children

e placement stability is a key factor in protecting against mental health problems.
5 With regard to policy:

a a number of policy documents published in the past few years are concerned with improving life chances for looked after children

b problems with recruiting and retaining foster carers and social workers is preventing improvements from taking place for looked after children

c complex care panels have been set up nationally to encourage all agencies to work collaboratively

d child and adolescent mental health services usually include looked after children in their generic caseload

e emerging models that child and adolescent mental health services are adopting for looked after children must be evaluated.

\title{
INVITED COMMENTARY ON Mental health of looked after children
}

Richardson \& Lelliott (2003, this issue) highlight the multiple and complex mental health, social and educational needs of looked after children and young people. A number of recent policies in the UK have defined this vulnerable client group as a priority for commissioners and practitioners, and have called for greater inter-agency partnerships to meet their needs. Descriptive and longitudinal research has established the characteristics of looked after children, their social and mental health outcomes and their poor access to services. The latter is related to children's frequently changing placements, disengagement and lack of advocacy, as well as to the fragmented and uncoordinated involvement of agencies. The remit of mental health service input is often not clearly defined and it inevitably overlaps with placement and social issues. In an extension of the UK national mental health survey, Meltzer et al (2000) are currently investigating the nature and prevalence of psychiatric disorders among children in foster and residential care. But how can we best meet their needs, and what should be the focus of future service development and research?

Looked after children should receive prompt and continuing treatment within comprehensive child and adolescent mental health services (CAMHS). However, this may not be universally possible until CAMHS are adequately resourced to respond to primary care referrals (i.e. from general practitioners, 
schools and community paediatricians), which often take precedence in service referral pathways. For this reason, services have developed alternative and more accessible models for vulnerable and mobile groups of children, through designated time offered by existing specialist mental health staff, development of jointly commissioned posts, and designated teams. Designated posts integrated within specialist CAMHS may be appropriate for smaller districts and rural/semi-urban areas, whereas designated teams may be more effective in inner-city areas. Such a team has been set up in Leicestershire, offering direct access and treatment to looked after children, and consultation and training to carers and staff (foster carers, social workers, residential care staff) (Callaghan et al, 2003b). The service applies the same principles to other transitional populations, such as young offenders, the homeless and refugees / asylum-seekers (Vostanis, 2002; Callaghan et al, $2003 a$ ). Emerging service models require evaluation on a number of outcomes.

There is very limited evidence from intervention trials with looked after children, predominantly because of the methodological difficulties involved (e.g. the number of confounding factors and comorbid psychiatric disorders). Research knowledge from other groups of traumatised children indicates the future priorities for clinicians and researchers. The diagnostic concept of attachment difficulties or disorders has not been fully validated, and there have been limited anecdotal reports on their treatment, usually by psychotherapeutic modalities, often with the involvement of carers (Boris et al, 1998). Cognitive-behavioural and psychodynamic psychotherapies have been associated with positive outcomes for post-traumatic stress disorders (Vostanis, 2003). However, little is known on their effectiveness for children who may have experienced long-standing adverse life events, predominantly abuse and neglect. Findings from parenting interventions (group and individual) need to be adapted for foster carers and for those in the early stages of the adoption process. As looked after young people often require different levels of intervention - within their foster or residential home, their school and in the community - the application of multisystemic therapy would be of particular interest (Henggeler et al, 1998).

Training is another essential component of mental health services for looked after children. A substantial proportion of children, mainly those with oppositional disorders, can be successfully managed by involving foster carers and their link workers, residential staff and social workers. Training should include the promotion of mental health and associated protective factors, the detection of more-serious problems such as depressed mood and suicidal ideation for referral to specialist services, and behavioural management (Minnis et al, 2001; Sebuliba \& Vostanis, 2001). This will ensure that all agencies maximise their skills and resources, and contribute to the child's care plan.

Mental health services for looked after children need to be developed within an integrated CAMHS model. Their planning, commissioning and implementation require ongoing inter-agency partnerships between health and local authority agencies. Hopefully, such partnerships will be facilitated by the National Service Framework and the forthcoming 'children's trusts'.

\section{References}

Boris, N., Zeanah, C., Larrieu, J., et al (1998) Attachment disorders in infancy and early childhood: a preliminary investigation of diagnostic criteria. American Journal of Psychiatry, 155, 295-297.

Callaghan, J., Young, B., Pace, F., et al (2003a) Mental health support for youth offending teams. Health and Social Care in the Community, 11, 55-63.

-, - - - et al (2003b) Evaluation of a new mental health service for looked after children. Clinical Child Psychology and Psychiatry, in press.

Henggeler, S., Schoenwald, S., Borduin, C., et al (1998) Multisystemic Treatment of Antisocial Behaviour in Children and Adolescents. New York: Guilford Press.

Meltzer, H., Gatward, R., Goodman, R., et al (2000) Mental Health of Children and Adolescents in Great Britain. London: Office for National Statistics.

Minnis, H., Pelosi, A., Knapp, M., et al (2001) Mental health and foster carer training. Archives of Disease in Childhood, 84, 302-306.

Richardson, J. \& Lelliott, P. (2003) Mental health of looked after children. Advances in Psychiatric Treatment, 9, 249256.

Sebuliba, D. \& Vostanis, P. (2001) Child and adolescent mental health training for primary care staff. Clinical Child Psychology and Psychiatry, 6, 191-204.

Vostanis, P. (2002) Mental health of homeless children and their families. Advances in Psychiatric Treatment, 8, 463469.

- (2003) Post-traumatic stress disorders in Palestinian children: lessons from the Gaza studies. International Journal of Psychiatry, in press.

Panos Vostanis Professor of Child and Adolescen Psychiatry, University of Leicester (Greenwood Institute of Child Health, Westcotes House, Westcotes Drive, Leicester LE3 0QU, UK. Tel: 0116 2252885; fax: 0116 2252881; email: pv11@le.ac.uk). 